is useful to have details of the proposed frequency during weekdays and weekends, as well as the population covered.

\section{Clinical facilities}

\section{Current provision}

The style of clinical service which is proposed may of course vary considerably from one situation to another, perhaps with differing degrees of emphasis on hospital and community based facilities. Nevertheless each consultant in general psychiatry requires adequate direct access to a range of resources and the proposed way in which existing facilities will be shared needs to be made quite clear. Such details should be provided with regard to in-patient beds as well as day patient and out-patient facilities.

\section{Projected developments}

It is always very useful to have details of any service developments which may be envisaged. Where there is a serious current deficiency in resource provision it is particularly important to have a statement that plans are well laid by the relevant authority so that the deficiencies will be rectified in the near future. $A$ statement should be made as to whether or not there are specific resources available to the development of an area of interest. If no such resources are available, a statement should be made as to the prospect of their becoming available.

\section{Research}

If the job description suggests that sessional time will be made available for research, then the clinical load should be compatible with this and support facilities must be adequate to render it a feasible proposition.

\section{Supporting staff and other facilities}

A consultant in general adult psychiatry may reasonable expect to work closely with a clearly identified multidisciplinary clinical team which can provide support which is adequate and appropriate to the size of the clinical practice envisaged. The team would normally consist of non-consultant medical staff together with colleagues in social work, clinical psychology, occupational therapy and nursing staff, including community psychiatric nurses. There also needs to be adequate provision of secretarial help, particularly when there is likely to be a considerable amount of administration involved, as in the development of community facilities which require liaison with several other agencies. The consultant would also reasonably expect to be provided with unshared appropriately equipped office space in at least one main clinical base.

\section{Approved by the Court of Electors April 1991}

\section{Reference}

WATsON, J. P. (1986) Calculating a district's psychiatric manpower. Bulletin of the Royal College of Psychiatrists, 10, 334-337.

\title{
General practice funding: the scope of the hospital element
}

\section{Recent Circular from the NHS Management Executive}

The College has been informed that all mental health referrals will be charged to GP budget holders from April 1993. However, the College continues to be concerned over the issue of psychiatric referrals in relation to GP fund-holding, in particular the anomaly whereby there is to be a charge through the GP budget for referrals to consultant psychiatrists and occupational therapists but not to other members of the mental health team.

We have received an explanation from the Management Executive as to why this decision was made. They appreciate the difficulties which will arise if GPs alter fundamentally their referrals by referring patients to CPNs who would then, if necessary, refer on to the consultant (in which event it would not be charged to the fund). They hope eventually to bring all mental health referrals under the scope of the scheme and FHSAs have been asked to monitor GP referral patterns to establish whether any significant change would be identified which might be due to CPNs and psychologists being regarded as a 'free good' in which case they have been asked to take up this point with the practice concerned.

I would be very grateful if any member of the College who has noticed such a change in the pattern of referrals from GPs could contact me in writing. I would like to collect evidence on this matter which can then be submitted, if necessary, to the Chief Executive of the NHS Management Executive.

Professor A. C. P. Sims

October 1991 